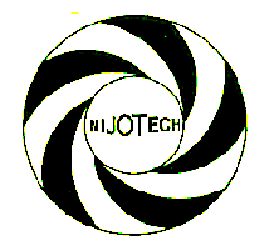

Nigerian Journal of Technology (NIJOTECH)

Vol. 33. No. 2, April 2014, pp. 238 - 244

Copyright@ Faculty of Engineering,

University of Nigeria, Nsukka, ISSN: $1115-8443$

www.nijotech.com

http://dx.doi.org/10.4314/njt.v33i2.14

\title{
SINGLE-PHASE DC-AC BOOST CONVERTER
}

\author{
C. I. Odeh* \\ DEPARTMENT OF ELECTRICAL ENGINEERING, UNIVERSITY OF NIGERIA, NSUKKA, NIGERIA \\ E-mail address: charles.odeh@unn.edu.ng
}

\begin{abstract}
This paper describes a new power conversion circuit topology for single-phase DC-AC boost converter, based on the dc-dc boost converter. It comprises an H-bridge, fed from a single input dc source through a boosting inductor. Change of load current flow is achieved with four current-steering diodes. The proposed boost inverter configuration performs single stage power conversion, which minimizes switching losses and attains higher efficiency as compared to the conventional boost inverter. The steady-state operating principle of the power circuit configuration and control strategy are described. A multi-loop structure controller is used to ensure a high dynamic performance. Computer simulations demonstrate the feasibility of the proposed boost inverter.
\end{abstract}

Keywords: inverter, boost converted, total harmonic distortion (THD).

\section{INTRODUCTION}

Conventional voltage source inverters (VSI) used in photovoltaic systems (PV), uninterruptible power supply (UPS) AC motor drives and other power supply systems, need to step-up the DC input voltage. To increase the output voltage level in order to meet load requirements, DC-DC boost converter is used to provide DC bus voltage for PWM inverters. Hence, the conventional design always cascades DC-DC converter and a separate DC-AC converter. The combined losses of the two inter-connected converter units contribute to low system efficiency. The cascaded double-stage design also makes for extra parts, greater system size and weight, [1-3]. The requirement of high voltage storage battery leads to high cost and reduced reliability, since the number of storage devices increases. An alternative design was presented in [4] wherein a boost inverter topology was implemented with two DC-DC boost converters from a view of low cost as shown in figure 1 (a). This design, however, requires two boost converters to operate simultaneously in order to generate the AC output voltage. This leads to complicated control system design.

To alleviate the above shortcomings, this paper proposes a new design for high performance singlephase boost inverter based on switch-mode DC-DC boost converter, as shown in Figure 1(b). Only one boost converter operates either in the positive or negative half cycle, allowing reduced inverter size, increased efficiency and simpler controllers.
In this paper, the multi-loop feedback control strategy, [5-9], which consists of an inner current loop for regulating the inductor current and an outer voltage loop for regulating the output voltage, is employed to control the boost inverter.

In addition, the feed-forward compensation, [10-13], for disturbance rejection is introduced to make the output voltage and inductor current track their commands closely, thus the output voltage can be well regulated.

\section{SYSTEM ANALYSIS}

\subsection{Operating principle of the boost inverter}

The proposed boost inverter circuit configuration, with the controllers, is shown in figure 2. It consists of full-bridge power stage $\left(S_{1}-S_{4}\right)$, diodes $\left(D_{1}-D_{4}\right)$, inductor L, DC capacitors $\left(\mathrm{C}_{1}\right.$ and $\left.\mathrm{C}_{2}\right)$, current controller, and voltage controller. The full-bridge arrangement allows direction change of the load current flow. The proposed boost inverter operates in continuous current mode (CCM) with a fixed switching frequency, as depicted in figure 3 . The load is connected differentially across the two DC capacitors. By sinusoidally modulating the switchmode DC-DC converter output voltage in each half cycle, two DC-offset voltages ( $\mathrm{V}_{\mathrm{DC} 1}$ and $\mathrm{V}_{\mathrm{DC} 2}$ ) are obtained across each DC capacitor and displaced mutually $180^{\circ}$ phase shift with each order. The output voltage $\mathrm{v}_{\mathrm{o}}$ is given by

$v_{o}=v_{D C 1}-v_{D C 2}$

\footnotetext{
* Corresponding author, Tel: +234-8038814698
} 

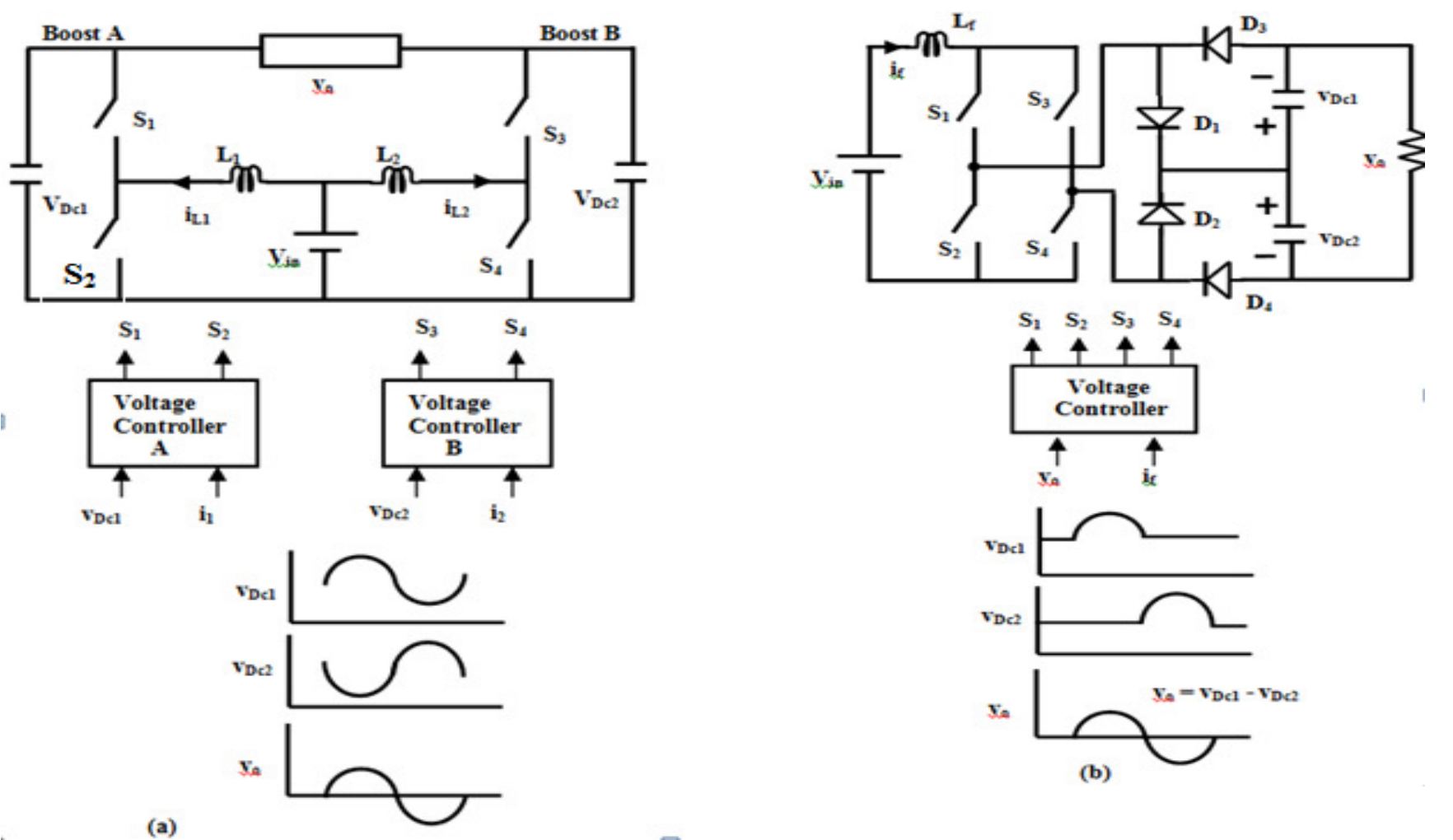

(a)

Figure 1. Boost inverter configurations: (a) Conventional boost inverter. (b) Proposed boost inverter.
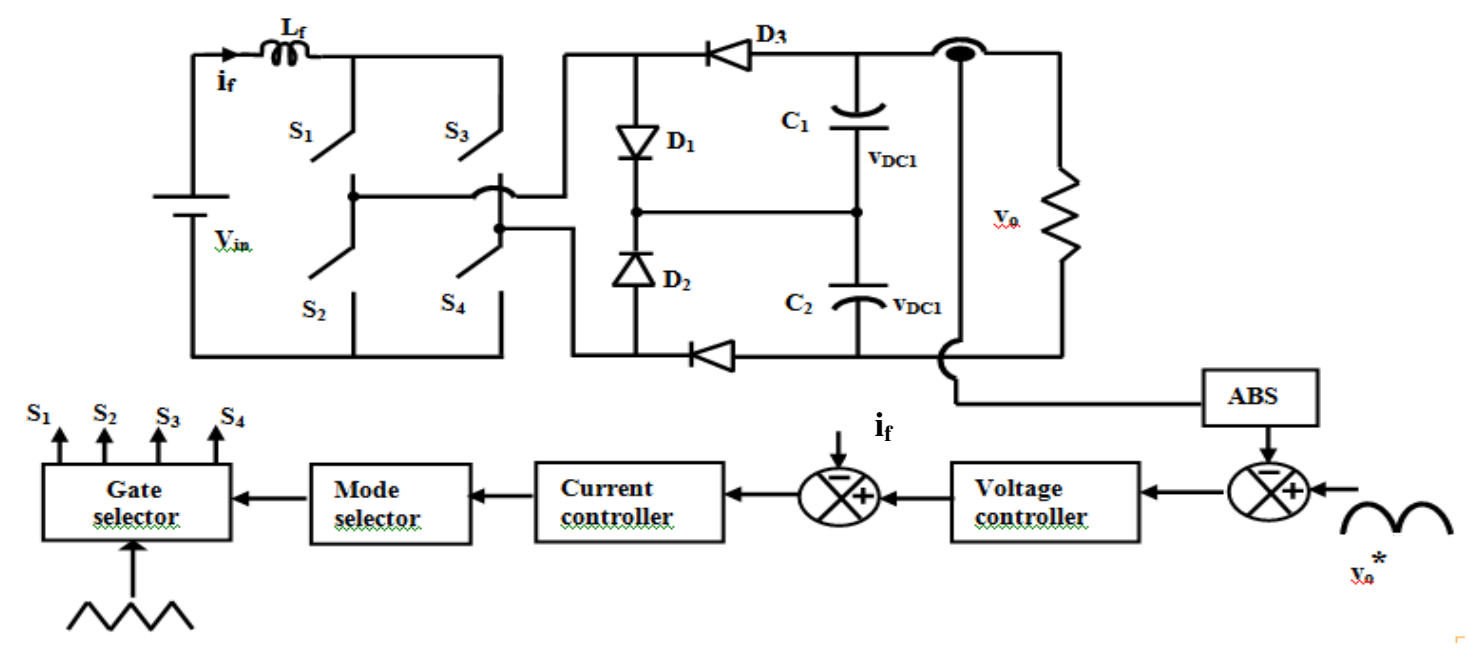

Figure 2. Power circuit and controllers for the proposed boost inverter.

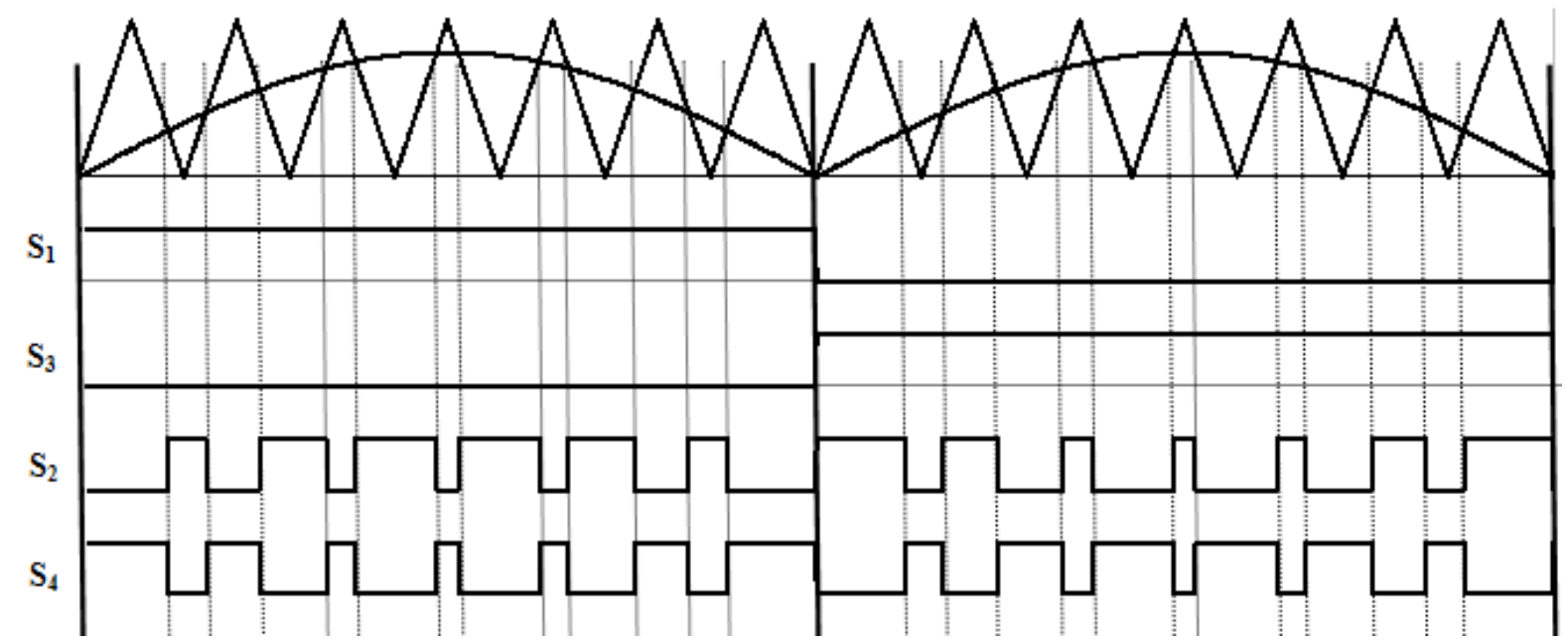

Figure 3: Simple PWM modulation scheme for the proposed boost inverter. 
The operation of the boost inverter can be divided into two stages for each half cycle. Four different modes are included over one complete cycle of operation. The corresponding equivalent circuit during each mode is shown in Figure 4 and explained below.

When switches $S_{1}$ and $S_{2}$ are turned on in the positive half cycle, the inductor current increases, storing energy in the inductor. During this mode, energy stored in capacitor $C_{2}$ is transferred to the load. Next, switches $S_{1}$ and
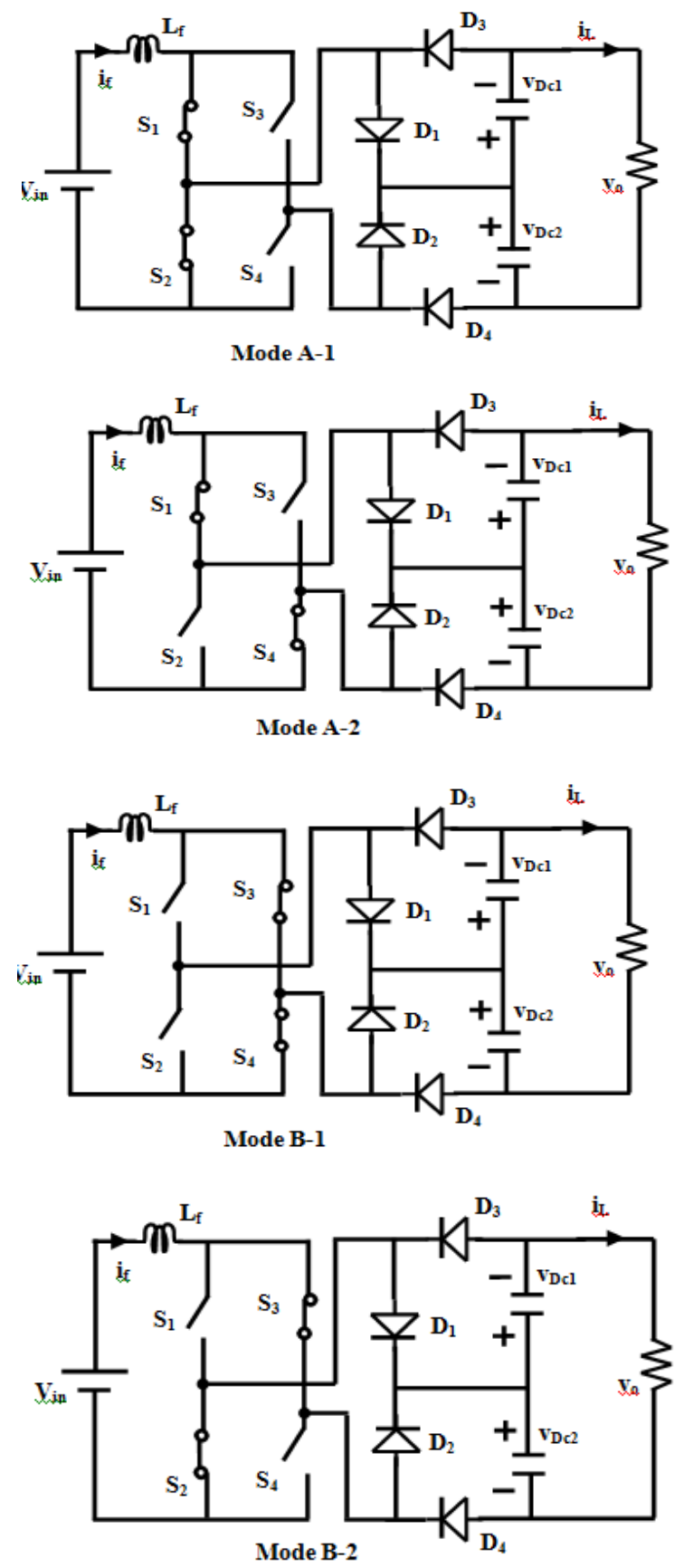

Figure 4. Modes of operation of the proposed boost inverter

The switch $S_{4}$ are turned on, the energy in the inductor is transferred to the load and capacitor $\mathrm{C}_{2}$ through $\mathrm{D}_{1}$ and $\mathrm{D}_{4}$, and thus the capacitor $\mathrm{V}_{\mathrm{DC}}$ increases. Similarly, for negative half cycles, switches $\mathrm{S}_{3}$ and $\mathrm{S}_{4}$ are both turned on. The inductor current increases linearly; storing energy in inductor. Meanwhile, the energy in capacitor $C_{1}$ is delivered to the load. Then, turning on $S_{3}$ and $S_{2}$ releases the energy stored in the inductor to the load and charges capacitor $\mathrm{C}_{1}$, through $\mathrm{D}_{3}$ and $\mathrm{D}_{2}$. Table 1 shows the switching States for each operational mode.

The mode selector in figure 2 is responsible for generating the desired control signals for the power switches $\left(\mathrm{S}_{1}-\mathrm{S}_{4}\right)$ according to the mode switching relation given in Table $1 . S_{1}$ and $S_{3}$ operate at the fundamental frequency, changing the current direction to the load every half cycle. $S_{2}$ and $S_{4}$ are turned on and off according to the comparison between a high frequency triangular carrier signal and a rectified modulating signal. The diodes $\left(D_{1}\right.$ to $\left.D_{4}\right)$ are used to protect the capacitors from being negatively charged. Compared to the four high frequency power switches of conventional boost inverter [1], the proposed design uses only one high frequency power switch in each half cycle. The proposed design's reduction in the number of switching operations results in significantly improved system efficiency and reliability.

Table 1: Switching states for each operational mode

\begin{tabular}{|c|c|c|c|c|}
\hline \multirow{2}{*}{$\begin{array}{c}\text { Output voltage } \\
\text { mode }\end{array}$} & \multicolumn{2}{|c|}{$\mathrm{V}_{0}>0$} & \multicolumn{2}{c|}{$\mathrm{V}_{0}<0$} \\
\cline { 2 - 5 } & $\mathrm{A}-1$ & $\mathrm{~A}-2$ & $\mathrm{~B}-1$ & $\mathrm{~B}-2$ \\
\hline $\mathrm{S}_{1}$ & ON & ON & OFF & OFF \\
\hline $\mathrm{S}_{2}$ & ON & OFF & OFF & ON \\
\hline $\mathrm{S}_{3}$ & OFF & OFF & ON & ON \\
\hline $\mathrm{S}_{4}$ & OFF & ON & ON & OFF \\
\hline
\end{tabular}

\subsection{Circuit modeling of the boost inverter}

\subsubsection{Mode $A-1$ and $B-1$}

$L_{f} \frac{d i_{f}}{d t}=V_{i n}$

Mode A-1: $C_{2} \frac{d v_{D C 2}}{d t}=\frac{v_{D C 1}-v_{D C 2}}{R_{L}}$

Mode B-1: $\quad C_{1} \frac{d v_{D C 1}}{d t}=-\frac{v_{D C 2} v_{D C 1}}{R_{L}}$

\subsubsection{Mode $A-2$ and $B-2$}

Mode A-2: $L_{f} \frac{d i_{f}}{d t}=V_{i n}-v_{D C 2}$

$C_{2} \frac{d v_{D C 2}}{d t}=i_{f}-\frac{v_{D C 2}-v_{D C 1}}{R_{L}}$

Mode B-2: $L_{f} \frac{d i_{f}}{d t}=V_{i n}-v_{D C 1}$

$C_{1} \frac{d v_{D C 1}}{d t}=i_{f}-\frac{v_{D C 1}-v_{D C 2}}{R_{L}}$ 
By introducing the following substitutions into (2) (4):

$$
\begin{gathered}
v_{o}=V_{o}+\widehat{v_{o}} \\
v_{i n}=V_{i n}+\widehat{v_{\text {in }}} \\
i_{f}=I_{f}+\widehat{\iota_{f}} \\
d=D+\hat{d}
\end{gathered}
$$

Where: $V_{o}, V_{i n}, I_{f}, D_{o}$ are the steady-state values of the output voltage, input voltage, inductor current and operating duty cycle, respectively; $\widehat{v_{o}}, \widehat{v_{l n}}, \widehat{, l_{f}}, \widehat{d}$ are the corresponding transient values.

which result in steady-state voltage and current:

$V_{o}=\frac{1}{1-D} V_{\text {in }}$

$I_{f}=\frac{1}{1-D} \frac{V_{o}}{R_{L}}$

Then, weighting the equations (2) - (4), the corresponding state space average modeling equations can be obtained as

$L_{f} \frac{d i_{f}}{d t}=v_{i n}-v_{o} d^{\prime}$

$C \frac{d v_{\text {in }}}{d t}=i_{f} d^{\prime}-\frac{v_{o}}{R_{L}}$

$d=1-d^{\prime}$

Based on (6), the time averaged circuit model of the boost inverter, [10], can be determined as shown in figure 5 .

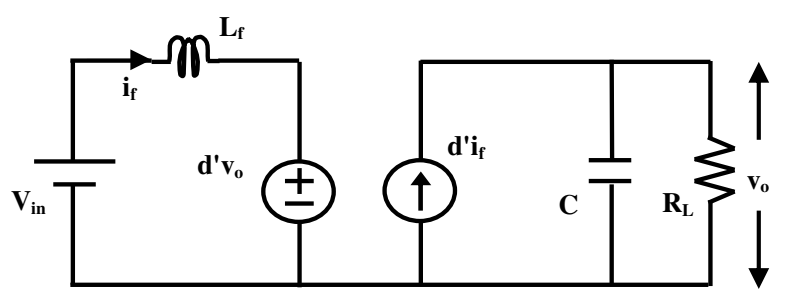

Figure 5. Average state space circuit model

\subsection{Control strategy}

From figure 5, the multi-loop control system block diagram of the proposed boost inverter is designed as shown in figure 6. A multi-loop controller which consists of an inner current loop and outer voltage loop is used to regulate the output voltage. A full-wave rectified signal is used to produce an AC reference voltage $\mathrm{V}^{*}$. The outer voltage loop generates the reference current command $\mathrm{i}_{\mathrm{f}}^{*}$ A common proportional plus integral (PI) controller is used to regulate the output voltage. The inner current loop compares the reference current command $\mathrm{i}_{\mathrm{f}}^{*}$ with the inductor current $i_{f}$. A proportional controller is used for the current loop. The output of this current loop is then compared with a triangular carrier, generating the desired gating signals for the switches. Additionally, feedback and feed-forward control techniques are employed in multi-loop to obtain desired tracking performance.

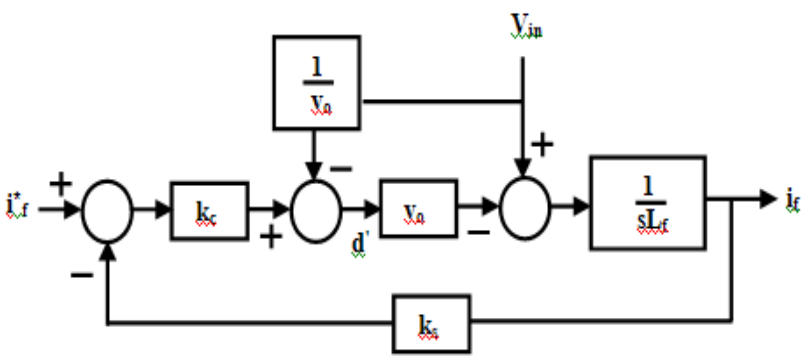

(a) Current control loop

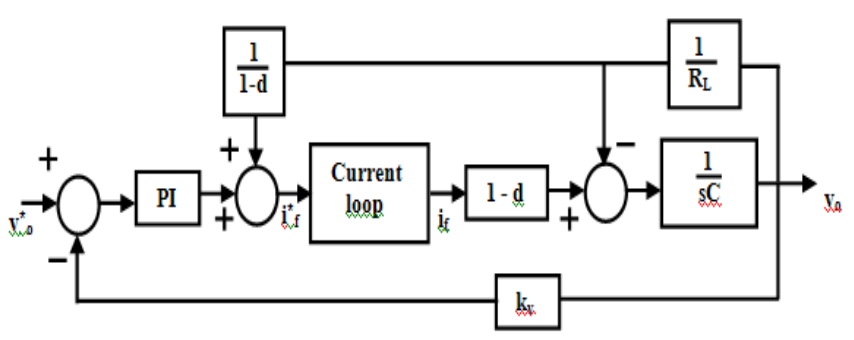

(b) Voltage control loop

Figure 6. Control block diagram of the proposed boost inverter

\section{SIMULATION RESULTS}

The performance of the proposed boost inverter is verified via computer simulation. The simulations are conducted using MATLAB SIMULINK and SIMPLORER software packages. Specifications of the circuit parameters in the simulations are given in table 1

Table 2: Circuit parameter specification.

\begin{tabular}{|l|}
\hline $\mathrm{V}_{\text {in }}=60 \mathrm{~V}$ \\
\hline $\mathrm{V}_{\mathrm{o}}=110 \mathrm{~V} \mathrm{rms}$. \\
\hline $\mathrm{L}_{\mathrm{f}}=0.7 \mathrm{mH}$ \\
\hline $\mathrm{R}_{\text {load }}=15 \Omega$ \\
\hline $\mathrm{C}_{1}=\mathrm{C}_{2}=220 \mu \mathrm{f}$ \\
\hline
\end{tabular}

The simulated results for resistive and rectifier loads are given in figures 7 and 8 . It shows that the output voltage can be kept closely to sinusoidal waveform with low distortion. It is also observed that the output voltage is obtained by the subtraction between two capacitor voltages, as earlier predicted. For multi-loop control system, the output voltage and current response to a step load change is also investigated by simulation and given in figure 9. The simulation results show that the output voltage can maintain sinusoidal waveform and fast response can be achieved. Furthermore, figures 10 and 11 illustrate that the harmonic contents of the output voltage can be kept at a very low level. The simulated waveforms and harmonic profiles of the output voltage evidently show that the proposed boost inverter can supply power to the load with good voltage regulation and low total harmonic distortion. 

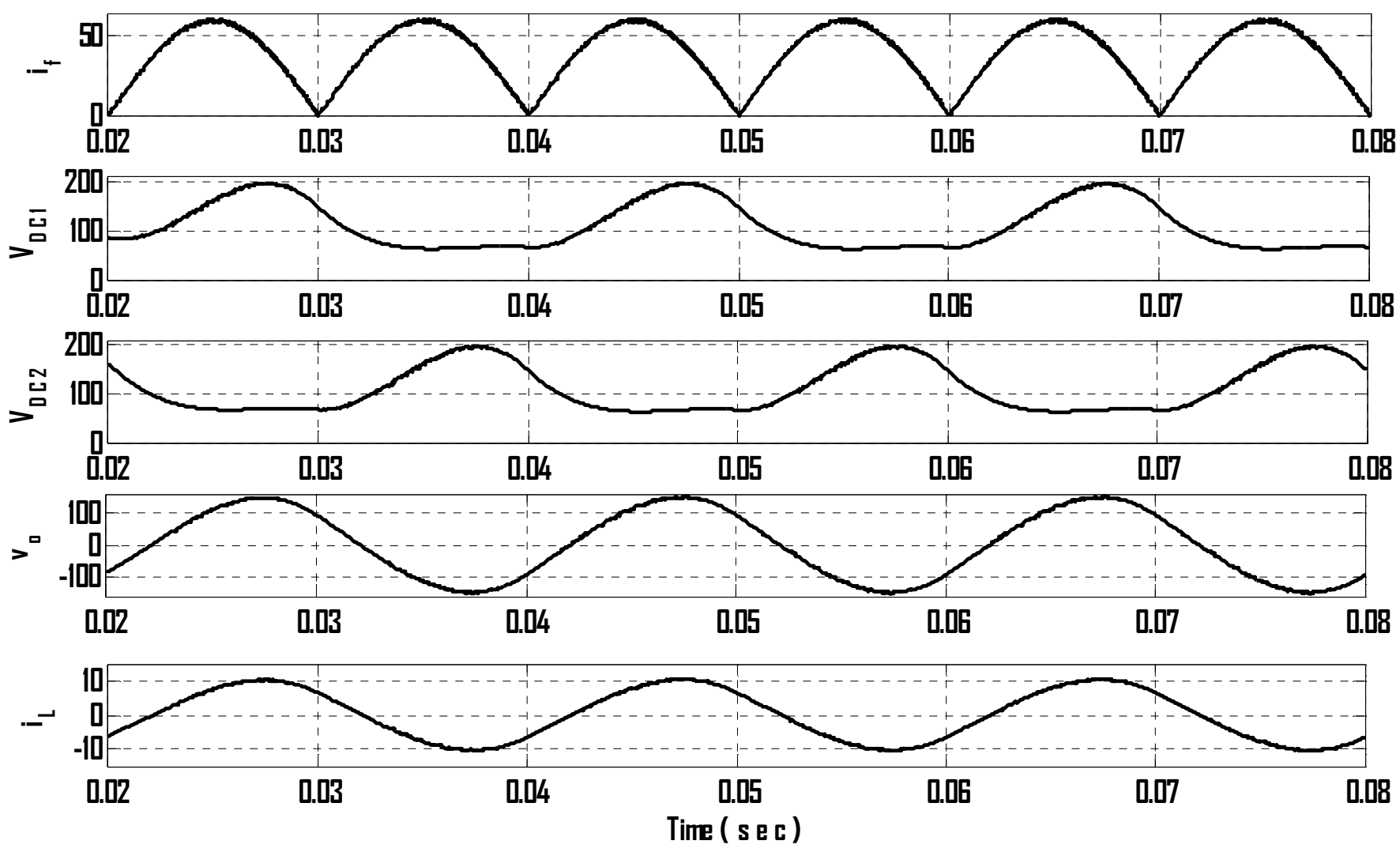

Figure 7. Simulated waveforms of resistive load.
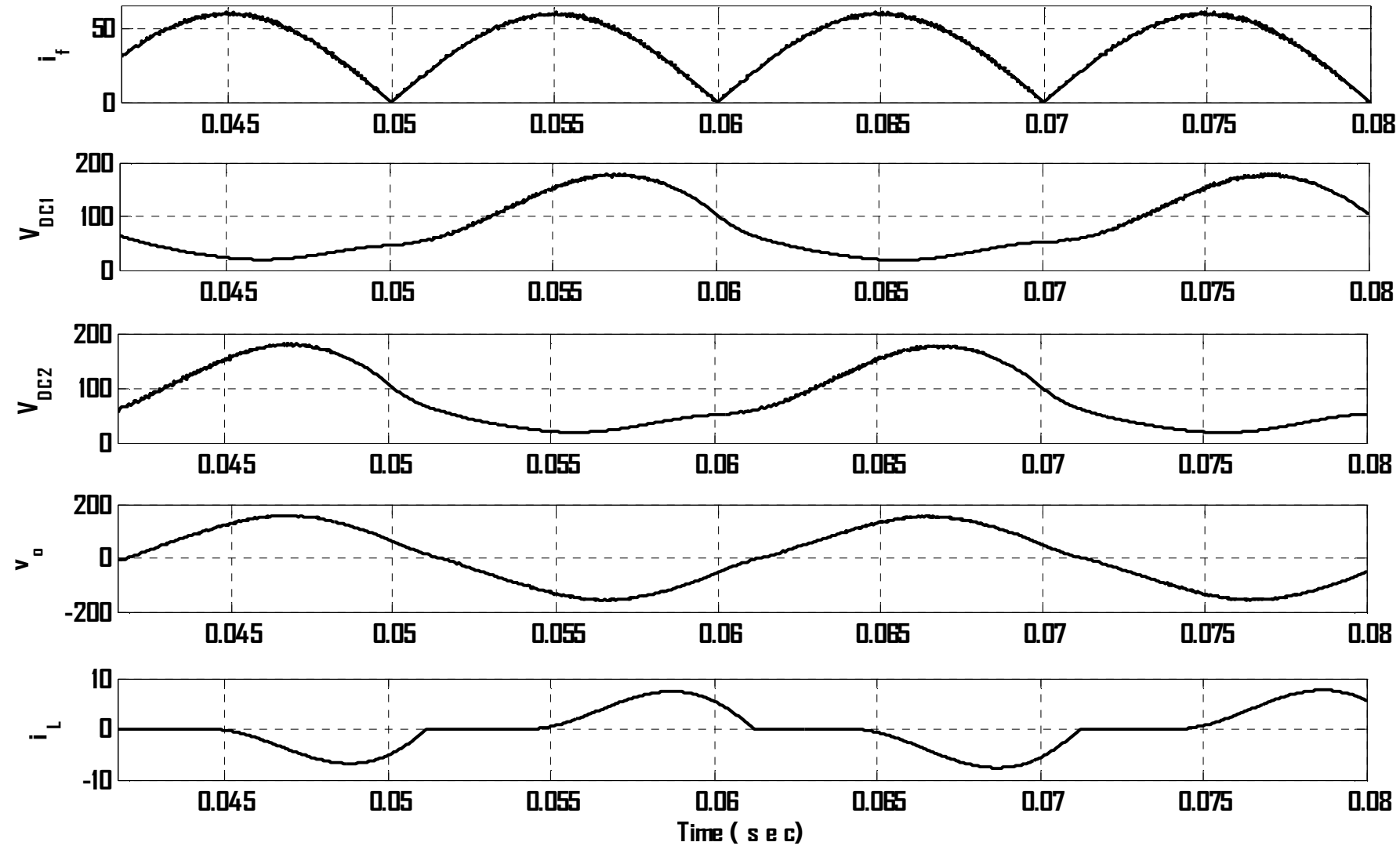

Figure 8: Simulated waveforms of rectifier load. 

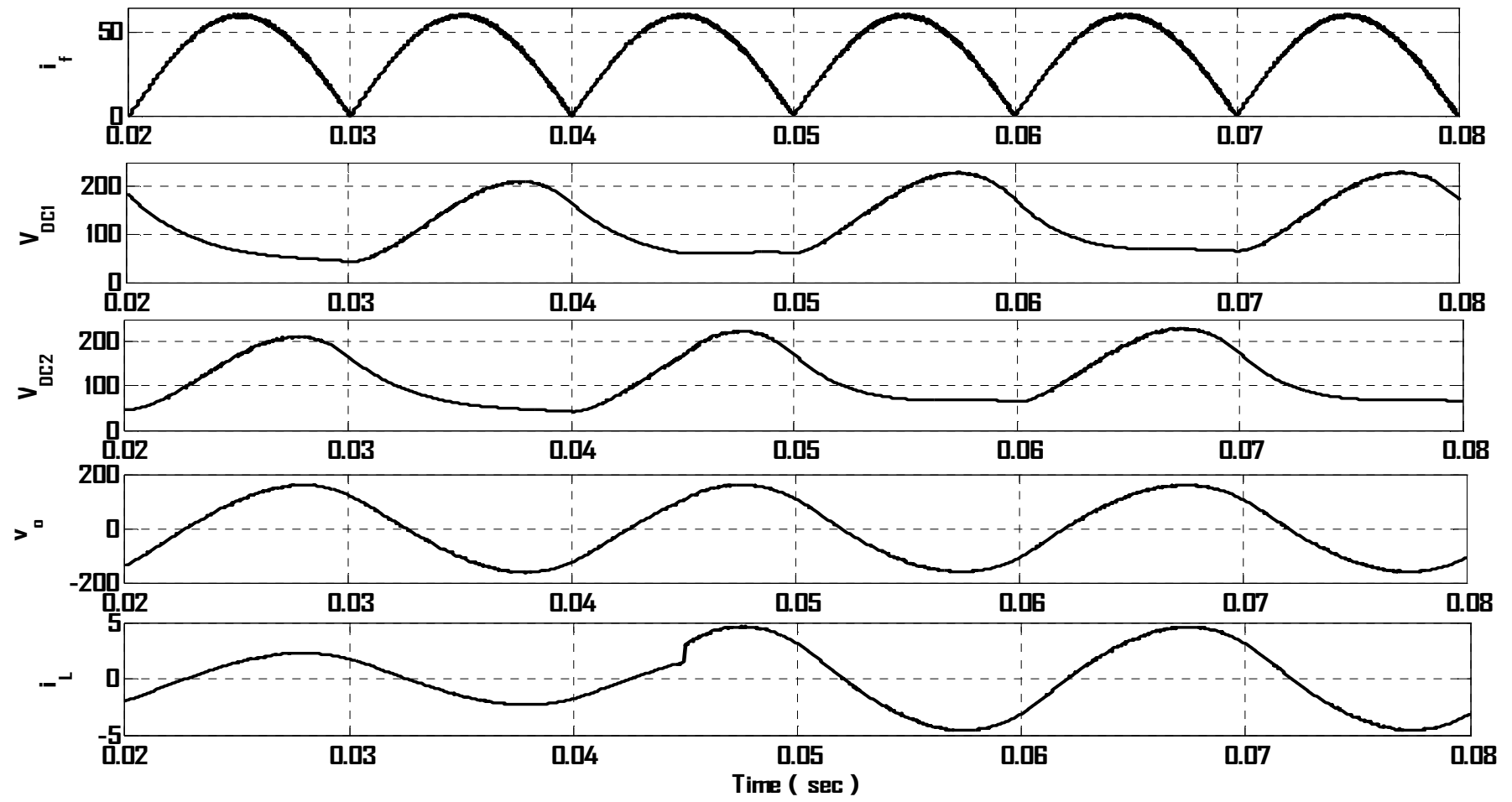

Figure 9. Simulated waveforms of output voltage and current response under step load change

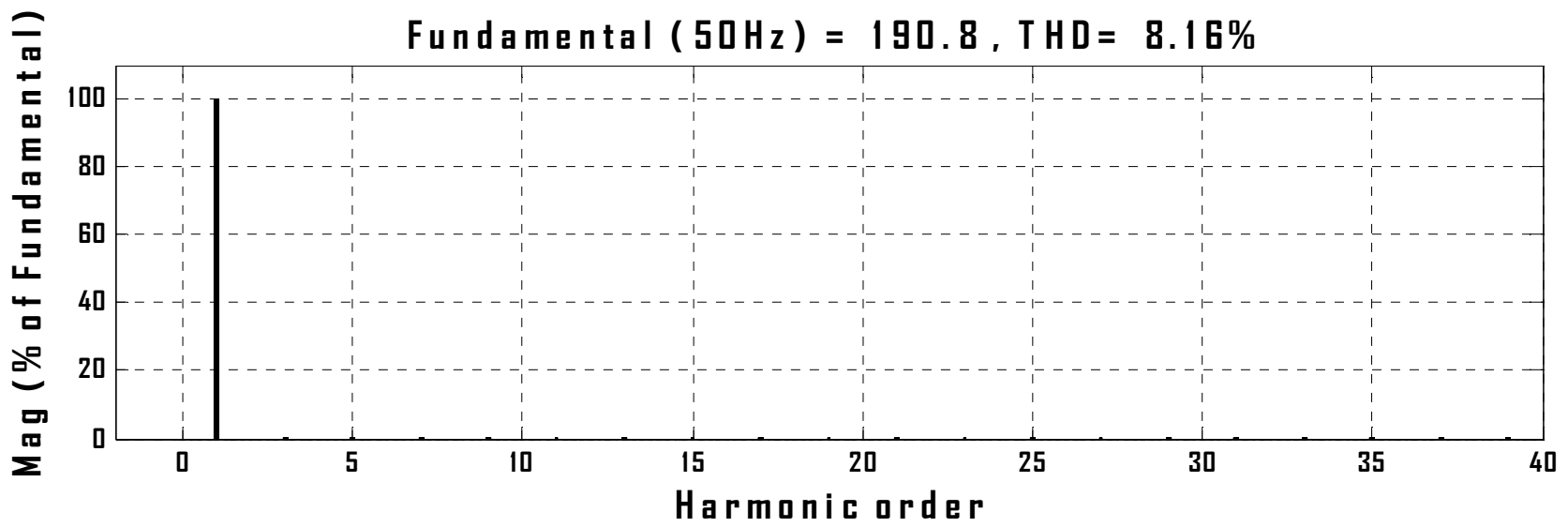

Figure 10. Simulated output voltage harmonic profile for resistive load.

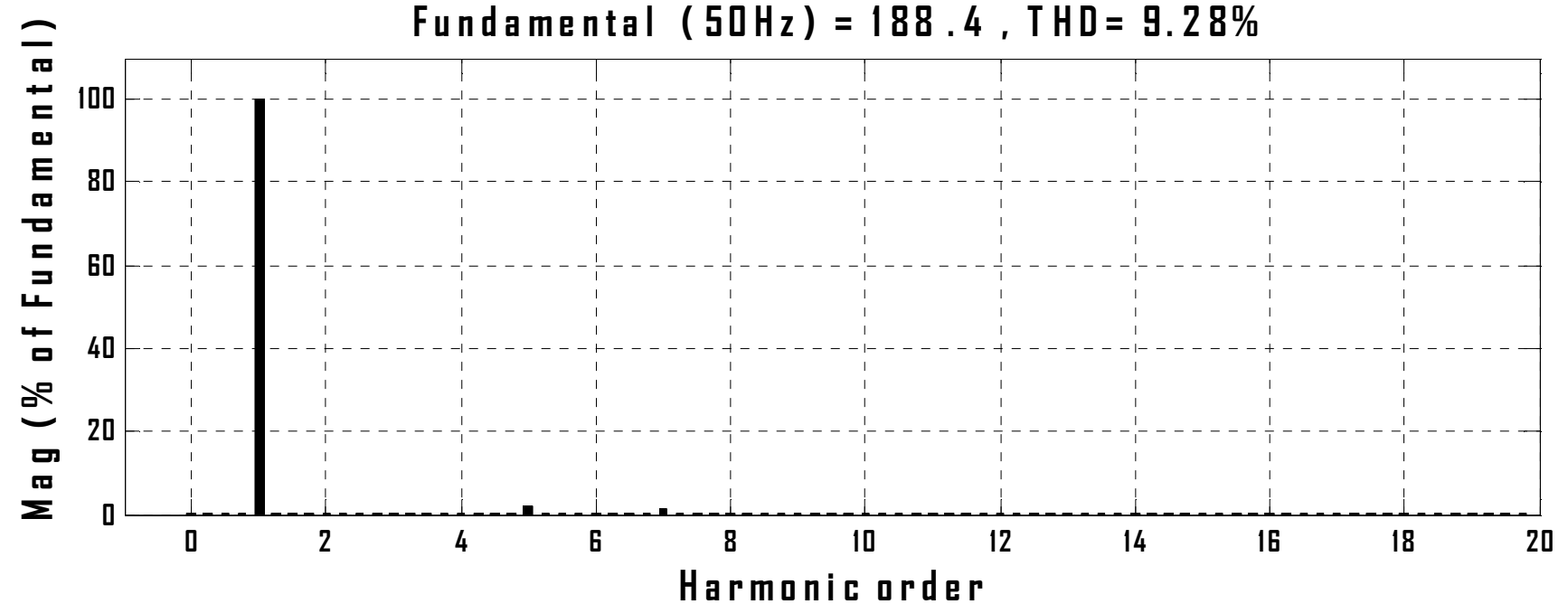

Figure 11. Simulated output voltage harmonic profile for rectifier load. 


\section{CONCLUSIONS}

A single-phase dc-ac boost converter configuration with reduced logic system controllers has been presented. The controller has simple architecture, requiring only one voltage control system. As a result, it offers the advantages of reduced complexity of control circuit. The other advantages of the proposed boost inverter over conventional boost inverter scheme can be summarized as follows:

(1) Simplified control scheme.

(2) High quality sinusoidal output voltage with nonlinear load.

(3) Reduced cost, size and weight compared to conventional systems.

Conclusively, the proposed boost inverter circuit offers a good harmonic profile and regulation of the synthesized output voltage waveform, as evidenced from the simulation study.

\section{REFERENCES}

[1] K. Hirachi, et al, "Cost-effective practical developments of a high performance and multifunctional UPS with new system configurations and their specific control implementations," IEEE PESC'95, pp. 480-485, 1995

[2] Bong Hwan Kwon, Jin-Ha. and Tae-Won Kim, “ Improved Single-phase Line-Interactive UPS," IEEE Trans. Ind. Electron., vol. 48, pp. 804-811, 2001.

[3] U. Herrmann, H. G. Langer, and H. Broeck, "Low cost DC to AC converter for photovoltaic power conversion in residential applications," Proc. IEEE Power Electronics Specialist Conference, PESC'93, pp. 588-594, 1993.

[4] Ramon O. Caceres. and Ivo Barbi, "A Boost DC-AC Converter: Analysis, Design and Experimentation ," IEEE Trans. Power Electronics, vol. 14, pp. 134141, 1999.
[5] J. E. Quaicoe, "Analysis and design of a multiple feedback loop control strategy for single-phase voltage source UPS inverter, "IEEE Trans. Power Electronics vol. 11, pp. 532-541,1996.

[6] Sang-Hoon Park, Young-Hwan Ryu, Won-cheol Lee, Jung-Hyo Lee, Jae-Sung Yu, Young-Ryul Kim, ChungYuen Won " A four-switch and half-bridge boost converter based BLDCM drive system for the DC-link voltage unbalancing compensation" in Proc. IEEE ICPE'07, 2007, pp 382-387.

[7] Changliang Xia, Zhiqiang Li, Peng Song, Yingfa Wang "A current control algorithm based on variable current threshold for four-switch three-phase BLDCM using intelligent controller" in Proc. IEEE ICIT, 2008, pp 1-8.

[8] A.Tripathi, P.C Sen, "Comparative analysis of fixed and sinusoidal hysteresis current Controller for voltage source inverters," IEEE Trans. on Industrial Electronics, Feb-1992, Vol.39, No.1, pp.63-73

[9] C.U. Eya, C.I. Odeh, D.B.N. Nnadi, M.U. Agu, S.E. Obe, "Utility Interfaced PWM of Solar Fed Voltage Source Inverter Using Fixed-band Hysteresis Current Controller Method, " Nigerian Journal of Technology, Vol. 31, No. 1, March, 2012, pp. 48-57.

[10] M. 1. Tyan. W. E. Brumsickle, and R.D. Lorenz, "Control topology options for single-phase Inverter," IEEE Trans. Industrial Applications, vol. 33, pp. 493500, 1997.

[11] P. Sanchis G.,O. Alonso Sadaba, L. Marroyo Palomo, T. Meynard, and E. Lefeuvre, "Variable operating (EPE01), Graz, Austria, pp. 27- 29, August 2001.

[12] Samir Kouro, Pablo Lezana, Mauricio Angulo and Jose Rodriguez, "Multicarrier PWM with DC- Link Ripple Feedforward Compensation for Multilevel Inverters, "IEEE Trans. Power Electronics vol. 23, no. 1,pp. 52-59, Jan. 2008.

[13] R.D.Middlebrook and $S$. Cuk, "A general unified approach to modeling switching converter Power stages, " in Proc. IEEE Power Electronics Specialist Conference, PESC'74 pp. 18-34, 1976. 